\title{
Do not eat the red food!: prohibition of snacks leads to their relatively higher consumption in children
}

Citation for published version (APA):

Jansen, E. L. G. M., Mulkens, S., \& Jansen, A. T. M. (2007). Do not eat the red food!: prohibition of snacks leads to their relatively higher consumption in children. Appetite, 49(3), 572-577.

https://doi.org/10.1016/j.appet.2007.03.229

Document status and date:

Published: 01/01/2007

DOI:

10.1016/j.appet.2007.03.229

Document Version:

Publisher's PDF, also known as Version of record

Document license:

Taverne

Please check the document version of this publication:

- A submitted manuscript is the version of the article upon submission and before peer-review. There can be important differences between the submitted version and the official published version of record.

People interested in the research are advised to contact the author for the final version of the publication, or visit the DOI to the publisher's website.

- The final author version and the galley proof are versions of the publication after peer review.

- The final published version features the final layout of the paper including the volume, issue and page numbers.

Link to publication

\footnotetext{
General rights rights.

- You may freely distribute the URL identifying the publication in the public portal. please follow below link for the End User Agreement:

www.umlib.nl/taverne-license

Take down policy

If you believe that this document breaches copyright please contact us at:

repository@maastrichtuniversity.nl

providing details and we will investigate your claim.
}

Copyright and moral rights for the publications made accessible in the public portal are retained by the authors and/or other copyright owners and it is a condition of accessing publications that users recognise and abide by the legal requirements associated with these

- Users may download and print one copy of any publication from the public portal for the purpose of private study or research.

- You may not further distribute the material or use it for any profit-making activity or commercial gain

If the publication is distributed under the terms of Article $25 \mathrm{fa}$ of the Dutch Copyright Act, indicated by the "Taverne" license above, 


\title{
Do not eat the red food!: Prohibition of snacks leads to their relatively higher consumption in children
}

\author{
Esther Jansen*, Sandra Mulkens, Anita Jansen \\ Faculty of Psychology, Department of Clinical Psychological Science, Maastricht University, P.O. Box 616, 6200 MD Maastricht, The Netherlands
}

Received 11 December 2006; received in revised form 22 March 2007; accepted 26 March 2007

\begin{abstract}
Overweight is becoming more prevalent in children. Parents' behaviours play an important role in children's eating behaviour and weight status. In addition to modelling and providing meals, parents also have an influence by using control techniques. One frequently used technique is restriction of intake. In this study, it was tested whether a prohibition of food in the first phase would lead to an increase in desire for the target food and overeating in the second phase. Sure enough, desire increased significantly in the prohibition group, whereas it remained constant in the no-prohibition group. Though no significant differences between groups were found in the absolute consumption of the target food, the proportion of consumed target food (target food intake/total food intake) was significantly higher in the prohibition group. Finally, children whose parents imposed either very little or a lot of restriction at home consumed more kilocalories during the whole experiment, as opposed to children who were exposed to a moderate level of restriction at home. These data indicate that restriction can have adverse effects on children's food preference and caloric intake.
\end{abstract}

(C) 2007 Elsevier Ltd. All rights reserved.

Keywords: Parental control; Child feeding practices; Restriction; Eating behaviour

\section{Introduction}

Obesity is considered one of the most serious health issues of the century. In the Netherlands, $46 \%$ of all adults are overweight (body mass index (BMI) $>25 \mathrm{~kg} / \mathrm{m}^{2}$; Centraal Bureau voor de Statistiek, 2006). Also among children, overweight is increasingly prevalent (Visscher, Kromhout, \& Seidell, 2002). At present, one out of seven Dutch children is overweight (TNO; van den Hurk et al., 2006). As childhood overweight often persists into adulthood (Clarke \& Lauer, 1993; Serdula et al., 1993), it seems of great importance to challenge this issue at a young age.

Parental behaviours are believed to play an important role in the development of children's weight status (see, e.g., Birch \& Fisher, 1995). Besides being role models and being responsible for purchases and cooking, parents also influence their children's food intake by using control techniques. According to Birch et al. (2001) parental

\footnotetext{
${ }^{*}$ Corresponding author.

E-mail address: e.jansen@psychology.unimaas.nl (E. Jansen).
}

control in the domain of eating can be subdivided into pressuring the child to eat healthy kinds of food (e.g., fruit and vegetables) and restricting intake of unhealthy, palatable (fatty or sweet) kinds of food. Nevertheless, overcontrolling children's food intake might have adverse effects on food preference and intake. It has been hypothesized that parents who overcontrol their children's food intake may interfere with their children's ability to self-regulate their intake. As a result, children would be more responsive to external cues (e.g., the smell and presence of food, rewards) as opposed to internal cues (e.g., hunger and satiety) (Faith, Scanlon, Birch, Francis, \& Sherry, 2004). In turn, this could result in disturbed eating behaviours like eating in the absence of hunger, restrained eating and eventually excess weight gain (Birch \& Fisher, 2000; Birch, Fisher, \& Krahnstoever Davison, 2003; Robinson, Kiernan, Matheson, \& Haydel, 2001). With regard to pressuring children to eat healthy kinds of food, researchers found it to be associated with lower fruit and vegetable consumption and picky eating in children (Galloway, Fiorito, Lee, \& Birch, 2001). In a more 
experimental design, Galloway, Fiorito, Francis, and Birch (2006) found that normal weight children consumed more soup and made fewer negative comments when they were not pressured to eat.

With regard to the effects of restriction, research in rats showed that, even without depriving energy, restricting access to alcohol can lead to significant increases in the consumption of alcohol when it is subsequently made available (Wayner et al., 1972). These results were replicated using an optional high-fat food as the restricted substance (Corwin et al., 1998).

So far, evidence for an adverse effect of restriction in humans is largely correlational. Several researchers have found parents' restraint over their children's food intake to be positively associated with children's weight status (Birch et al., 2003; Constanzo \& Woody, 1984). Although it may seem plausible that restriction behaviour by parents could lead to disturbed eating behaviour and subsequent overweight, the alternative could be that parents start restricting intake of palatable kinds of food when they observe their children becoming heavier. This problem of causality can be solved by manipulating restriction behaviour in a laboratory setting in normal weight participants.

A laboratory study by Mann and Ward (2001) examined the effect of food restriction in normal weight adults. Participants were assigned to either a forbid-choice condition or a forbid-reactance condition. All participants took part in three taste sessions of $5 \mathrm{~min}$ each. The first session was identical for both conditions: they were allowed to eat from all three kinds of candy, including a novel kind of candy. In the second taste session, the manipulation took place. Participants in the forbidreactance condition were not allowed to eat from the novel kind of candy, whereas participants in the forbidchoice condition were asked not to eat much of the novel kind of candy, because it was scarce, but also told that they were free to do so anyway. Finally, the third taste session was identical to the first one. The results showed that desire for the forbidden food remained high in the forbidreactance participants, whereas desire decreased in the forbid-choice participants. However, this constant level of desire did not lead to subsequent rebound eating in the forbid-reactance participants. Although palatable kinds of candy were used in the laboratory study, the forbidden food was a kind of candy that was novel to the participants. Therefore, one could argue that participants might not have had difficulties denying oneself this candy. It seems rational, thus, that rebound eating and increased desire do occur when participants are prohibited from wellknown palatable kinds of food that they are used to eat on a regular base.

Fisher and Birch (1999) studied the influence of restriction of palatable foods in children. In the experiment, 3-6-year-old children participated in eight group snack sessions: four unrestricted sessions, followed by four restricted sessions. The target food was a palatable snack food. The alternative was a food of lower preference.
During the unrestricted sessions, both types of food were freely accessible during $15 \mathrm{~min}$. During the restricted sessions, children had only one $5 \mathrm{~min}$ period of free access to the restricted food. The results showed that children's behavioural response (requests for the food, attempts to obtain it or comments about liking it) to the palatable snack food was greater during restricted sessions than during unrestricted sessions (Fisher \& Birch, 1999).

Summarized, research in adults shows an increased desire, but no rebound eating following restriction. Research in children shows that pressure to eat leads to a lower intake, thus an adverse effect. In addition, children show more behavioural responses when food is restricted. However, the effects of restriction in children have not been extensively tested yet. Considering the clinical relevance of mapping the effects of restriction, more experimental research in this area is highly desirable. In their study, Fisher and Birch (1999) presented a less attractive food as the alternative for the restricted food. Although this design probably corresponds more to a real life situation, the current study aims to examine the pure effect of restriction by providing an alternative food that is equal in taste.

The current study focuses on the possible adverse effects of external restriction of food intake in children. In this study we tested whether prohibiting snacks would result in an increased desire for forbidden food followed by overeating. We expected desire for the forbidden snacks to increase after the prohibition phase in the prohibition group, whereas we hypothesized that it would remain constant or even decrease during that same period in the no-prohibition condition. Secondly, it was expected that participants in the prohibition condition would eat relatively more forbidden snacks (in comparison with control snacks) in the second phase of the experiment, whereas we expected no differences between the two phases in the no-prohibition condition. The third and final hypothesis was that the degree of restriction in the home situation influenced overall food intake during the experiment: the more a participant was restricted at home, the more he would consume during the taste sessions.

\section{Method}

\section{Participants}

Seventy four participants were recruited from six different primary schools in the Netherlands, Germany and Belgium. Parents with children in primary school were approached and invited to let their children participate in the current study. Participants were told that the experimenter represented a sweets factory. As this factory was developing a new kind of sweet for children, the developers were very interested in how children evaluated existing snacks and sweets. The children were 5 and 6 year olds. The attraction of snacks is fairly strong in children, and we expected minimal social desirable behaviour concerning the 
eating of snacks in normal weight young children. Also, children in this age category are able to obey prohibitions (Piaget, 1965). Besides the fact that children under the age of 5 might not understand the content of a restriction, we also expected difficulties in assessing taste and levels of desire in children that young. In addition, older children could possibly experience feelings of shame and guilt to a greater extent than younger children. Permission was obtained from the participating schools as well as from the children's parents. Although the parents were not presented with the formulated hypotheses, they were told the study examined effects of prohibition. They were requested not to share this information with their children prior to their participation in the study. The study was approved by the ethical committee of the Faculty of Psychology, Maastricht University. Cooperating schools received a gift certificate afterwards. Participant characteristics are summarized in Table 1.

\section{Design}

Participants were randomly assigned (though controlled for gender) to one of the two conditions: a prohibition condition and a no-prohibition condition (between subjects factor). The experiment consisted of two phases (within subjects factor; during the first phase the prohibition manipulation took place, phase two was an "all you can eat" phase for both groups). Dependent variables were food intake in kilocalories, proportion of consumed prohibited snacks and desire for prohibited snacks.

\section{Measurements}

\section{Child Feeding Questionnaire (CFQ)}

Along with an informative letter about the study and an informed consent form, parents received the Dutch CFQ (Birch et al., 2001, translated with permission of the authors) to fill in. The CFQ is a measure of parental attitudes, beliefs and practices of child feeding and obesity proneness. The CFQ comprises 34 items spread over 7 factors, namely 'perceived feeding responsibility'; 'per-

\section{Table 1}

Age, gender, nationality and BMI percentiles of the prohibition group versus the no-prohibition group

\begin{tabular}{lll}
\hline & $\begin{array}{l}\text { Prohibition } \\
\text { group }\end{array}$ & $\begin{array}{l}\text { No-prohibition } \\
\text { group }\end{array}$ \\
\hline$N$ & 36 & 38 \\
Nationality distribution of & 14 German & 14 German \\
participants & 14 Dutch & 15 Dutch \\
& 8 Belgium & 9 Belgium \\
Age (mean (SD)) & $5.44(0.5)$ & $5.58(0.6)$ \\
Gender (boy/girl) & $19 / 17$ & $18 / 20$ \\
BMI (mean (SD)) & $15.8(3.3)$ & $15.0(3.1)$ \\
BMI percentile (mean (SD)) & $59.07(33.0)$ & $47.14(32.1)$ \\
\hline
\end{tabular}

There were no significant differences between groups regarding age, BMI percentile, nationality- or gender distribution. ceived child overweight'; 'perceived parent overweight'; 'concerns about child overweight'; 'restriction'; 'pressure to eat' and 'monitoring'. Every item is scored on a scale from 1 to 5 . The higher the score, the more parental control is exerted. The internal consistency of the 7 subscales is good; all 7 subscales have a Cronbach's $\alpha$ above 0.70 . As yet, the validity of the CFQ is unknown.

For the current study we were especially interested in the 'restriction' scale of the CFQ, considering our hypotheses. Therefore, only data from the 'restriction' scale were analysed.

\section{Snacks}

In this study, M\&M's chocolates and crisps were presented to the participants, both in colours red and yellow. Participants in the prohibition condition were prohibited from eating the red foods during phase one. We chose to forbid only a certain colour of food instead of prohibiting one kind of food, because sensory-specific satiety (SSS; Rolls \& Rolls, 1996) alone could account for an increased interest in other kinds of food. SSS refers to the 'decrease in pleasantness of a food after it has been eaten to satiety and other food not eaten to satiety remains relatively pleasant'. Instead we used two different kinds of snacks (sweet and salty), both presented in two colours: red and yellow. The two colours did not differ in taste, and therefore SSS could not account for an increased interest in the forbidden food.

The snacks were presented in four identical bowls: the bowls with crisps contained $45 \mathrm{~g}$ each; the bowls with M\&M's contained $400 \mathrm{~g}$ each.

\section{Desire to eat, taste and satiety}

To measure the desire to eat a particular kind of food, a Visual Analogue Scale (VAS) was used. The left extreme represented 'no desire to eat at all' and the right extreme represented 'a very large desire'. Emoticons were used to clarify these terms. Taste of the food types was measured with a five point rating scale (ranging from 'not tasty at all' to 'very tasty'). Finally, satiety was measured with a VAS scale (marking the left extremity meaning 'their tummy was totally empty' and marking the right extremity meaning 'their tummy was completely full'). Taste and satiety were measured before phase one to assure that the participants from the different groups did not differ in their taste ratings and were equally satiated before the experiment started. Desire was assessed at three moments: before phase one and after phases one and two.

Body mass index. Participating children's weight and height were measured once at the end of the session. Participants had their clothes on, coats and shoes off. Weight in kilograms, rounded off to one decimal, was measured by means of a digital scale. Height in centimetres, rounded off to one decimal, was assessed with measuring tape which was applied on the wall. The experimenters had undergone a short training in collecting this kind of 
information correctly. BMI's and BMI percentiles were calculated subsequently (children's BMI-percentile-for-age calculator; USDA/ARS Children's Nutrition Research Center, 2007).

\section{Procedure}

All children were individually tested. To this end, they were picked up from their class rooms (one by one) and asked to sit down in a quiet room where they were not distracted by other children or noises. The experimenter then introduced herself as a staff member of a sweet factory. The children were told that they had to answer various questions and to taste different kinds of food. Then the actual experiment started. Through a structured interview, the current levels of satiety, taste and desire of all four types of food were assessed. Additionally, they were asked about the frequency of eating snacks and sweets at home and whether they had to ask their parents for permission to eat snacks. After answering these questions the first phase began. Four bowls filled with snacks (one for each type of food) were presented during this phase. In both conditions, two different snacks (sweet and salty) were offered, each presented in two colours (red M\&M's, yellow M\&M's, red crisps and yellow crisps). A glass of water was placed on the table along with the snacks.

Children in the control condition were allowed to eat all types of food during this phase. Children in the prohibition condition were instructed not to eat the red kinds of food. The children were left alone during the actual tasting. After $5 \mathrm{~min}$, the experimenter returned to the room and took away the bowls which were weighed secretly in another room. Then, levels of desire for the different kinds of food were assessed. Photographs of the different types of food were placed in front of the child as a helping hand. Subsequently, the second phase started. During this phase, both conditions received the same instruction: they could eat as much as they wanted from all kinds of food. Again, the experimenter left the room during the tasting. After $5 \mathrm{~min}$, the experimenter returned and took the food outside the room and weighed the respective bowls. Finally, the child's weight and height were measured. The child was then guided back to the classroom. Afterwards, parents received a debriefing form which informed them about the hypotheses and expected results.

\section{Results}

Data for all 74 children were used in the analyses. Taste ratings and satiety levels before phase one did not differ between groups. Mean and SD's are listed in Table 2.

Hypothesis 1. Desire for the forbidden food increases during phase one in the prohibition group as compared to the no-prohibition group.

Difference scores for desire (desire after phase one minus desire before phase one) were calculated for all 74 participants. To determine whether a difference between groups regarding change in desire existed, a 2 (Group: prohibition versus no prohibition) $\times 2$ (Phase: one versus two) ANOVA was carried out. Further, simple effects were examined using $t$-tests.

The results showed a marginal significant interaction of group and phase regarding the course of desire $(F(1$, $72)=2.22, p=0.07$, one-tailed). $t$-Tests of simple effects show that desire roughly remained at the same level in the control group $(t \quad(37)<1)$, whereas desire increased significantly during phase one in the prohibition condition $(t(35)=2.24, p<0.05)$. See also Table 2 .

Hypothesis 2. Children in the prohibition condition consume more forbidden snacks in phase two.

For the second hypothesis we used a MANOVA to measure the differences between the 2 groups in the second phase regarding consumed kilocalories and proportion of red food (red food in grams divided by total amount of food in grams).

With respect to consumed amount in kilocalories no significant differences between groups were found (see also Table 2). However, the MANOVA indicated a significant difference between the two groups with respect to the proportion of consumed red snacks in phase 2 ( $F(1$, $72)=6.4, p<0.05)$. Children in the prohibition condition consumed a larger proportion of red snacks $(M=0.61$, $\mathrm{SD}=0.18)$ than children in the control condition $(M=0.5, \mathrm{SD}=0.19)$ during that same phase.

Control measures, desire and intake: prohibition group versus no-prohibition group

\begin{tabular}{llll}
\hline & $\begin{array}{l}\text { Prohibition group } \\
\text { Mean (SD) }\end{array}$ & $\begin{array}{l}\text { No-prohibition group } \\
\text { Mean (SD) }\end{array}$ \\
\hline Satiety before phase one (min. 1-max. 10) & $4.1(3.1)$ & $4.1(2.7)$ & Nalue \\
Taste red food (min. 0-max. 4) & $3.1(1.12)$ & $3.21(1.22)$ & NS \\
Taste yellow food (min. 0-max. 4) & $3.0(1.21)$ & $3.16(1.22)$ & NS \\
Desire before phase one (min. 1-max. 10) & $6.5(3.0)$ & $7.9(2.0)$ & NS \\
Desire after phase one (min. 1-max. 10) & $7.6(2.5)$ & $63.7(32.67)$ & NS \\
Intake in kilocalories from red food in phase two & $69.7(37.2)$ & $0.50(0.19)$ & NS \\
Intake in proportion of red food in phase two & $0.61(0.18)$ & & \\
\hline
\end{tabular}


Hypothesis 3. Children, whose parents are more restricting at home, consume more kilocalories during the experiment.

Hypothesis 3 was investigated using linear regression. Both the 'restriction' scale of the CFQ and a quadratic term of this scale were entered in the regression. Dependent variable was total food intake in kilocalories.

Analysis of the third hypothesis showed a curve linear effect: regression analysis indicated that the children of parents reporting a low level of restriction as well as the children of parents reporting a high level of restriction consumed more kilocalories during the whole experiment than the children of parents reporting a moderate level of restriction at home $\left(p<0.000, R^{2}=0.212\right)$. See also Fig. 1 . This means that $21 \%$ of the variance in the amount of consumed snacks can be explained by the (self-reported) restricting behaviour of the parents at home.

\section{Discussion}

The aim of this study was to test whether restricting children's snack intake would result in an increased desire for the forbidden food and subsequent overeating. To this end, we had 5- and 6-year-old children participate in a taste experiment in which they were either or not prohibited to eat a certain colour of snacks. It was expected that the children in the prohibition group would develop an increased desire for the forbidden food during the first phase. Also, they were expected to eat more from the formerly forbidden food in the second phase of the experiment during which the prohibition was no longer operative, as opposed to the children in the no-prohibition group.

The present results show that the desire to eat the forbidden food indeed increased after a prohibition. Next, although the absolute intake of the forbidden food did not differ between groups, the consumed proportion of

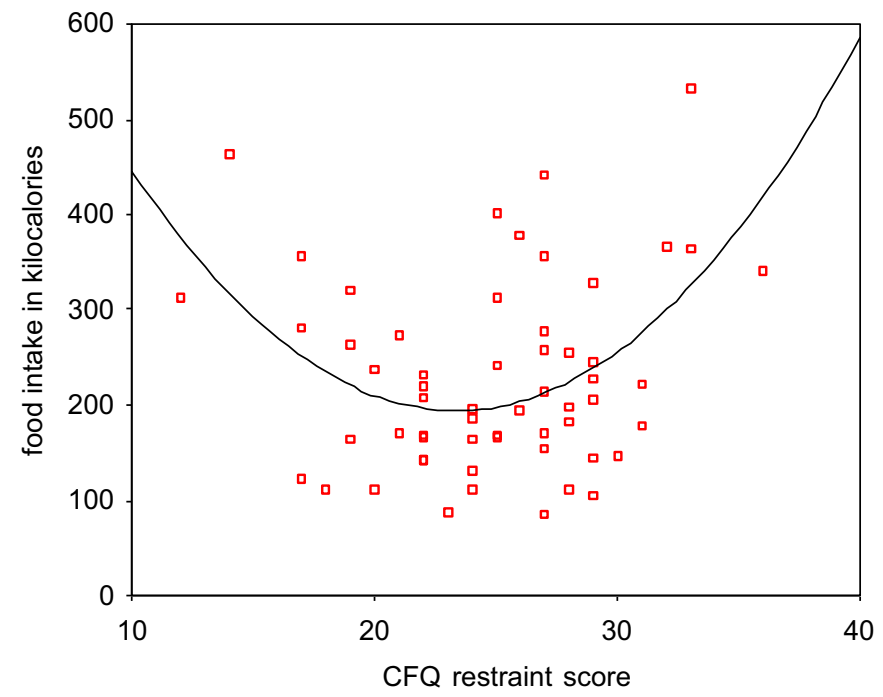

Fig. 1. The curve linear relationship between CFQ restriction scores and total intake in kilocalories. forbidden snacks (compared to the control snacks) was significantly higher in children in the prohibition group. This means that children who were prohibited from eating the red snacks in the first phase of the experiment ate relatively more from this food in the second phase than from the other (yellow) foods. Thus, our prediction that a prohibition of a certain snack would lead to a relatively greater consumption of this snack afterwards came true. Indeed was the formerly prohibited snack consumed relatively more often than the unforbidden one, as compared to the control group. The desire data support this behavioral outcome. The findings thus suggest that forbidden 'fruit' becomes more attractive.

The fact that desire already increased after a $5 \mathrm{~min}$ prohibition is interesting. Despite the fact that these children did not consume more kilocalories from red snacks after the prohibition, it could very well be that they develop some kind of obsessive interest for the forbidden food. In the current study, children in the prohibition group were offered similar attractive alternatives for the forbidden snacks (identically the same snacks, yet in a different colour), whereas in a home situation, parents often provide a far less attractive alternative (e.g., fruit) or no alternative at all. This could probably lead to other effects of the prohibition itself, including overeating.

Our third hypothesis regarded the relationship between parental restriction at home and snack intake during the experiment. Interestingly, parental restriction at home could predict overall food intake, regardless of the experimental condition of the child. It appeared that children whose parents imposed either very little or a lot of restriction at home consumed more kilocalories throughout the experiment, as opposed to children who were exposed to a moderate level of restriction at home. Though a causal relationship cannot be deduced from these data, this finding clearly is in line with earlier research on the relationship between restriction and weight status. In our study, however, only children with a normal weight participated. Replication and further research in this domain seem certainly worthwhile.

The findings of the current study support previous evidence for the idea that parents should be careful with restricting children's food intake in a rigid way as it makes them more eager for that food. It even might be the case that children eat more from those kinds of food, although the latter is based upon correlational data. Still, restricting children's food intake might not be an effective strategy when challenging overweight. Parents need to be enlightened about these adverse effects of restriction and provided with better alternatives. A difficulty that arises when advising parents is determining how moderate or normal control is defined or characterized. Further research seems necessary before guidelines can be formulated definitively.

A final point is that restricting food intake might also be used for positive purposes. If palatable foods can be made even more attractive by prohibiting them, it would be 
interesting to study whether the same holds true for less palatable kinds of food like vegetables and fruits. As a lot of children have difficulties consuming the daily recommended amounts of vegetables and fruits, it would be valuable to develop a method to promote their consumption.

The experimental nature of the current study makes the results a worthwhile addition to the current knowledge in this area. As this study was carried out in an experimental setting, it was possible to control more variables than would have been possible in a field study. Although we found relatively small group differences, these differences are significant and systematic. In addition, this experimental study allows us to cautiously determine the causal relation between restriction and food consumption. Therefore, the results can contribute to the comprehension of the development of overweight.

\section{Acknowledgement}

The authors would like to thank Jill Breuer, Maria Giannoulidou, Karin Joanknecht, Daniela Schneider, Danitsa Suart and Ine Ubben for their help in data acquisition.

\section{References}

Birch, L. L., \& Fisher, J. A. (1995). Appetite and eating behavior in children. Pediatric Nutrition, 42, 931-953.

Birch, L. L., \& Fisher, J. O. (2000). Mother's child-feeding practices influence daughters eating and weight. American Journal of Clinical Nutrition, 71, 1054-1061.

Birch, L. L., Fisher, J. O., \& Krahnstoever Davison, K. (2003). Learning to overeat: Maternal use of restrictive feeding practices promotes girls' eating in the absence of hunger. The American Journal of Clinical Nutrition, 78, 215-220.

Birch, L. L., Fisher, J. O., Mackey, C. N., Grimm-Tomas, K., Sawyer, R., \& Johnson, S. L. (2001). Confirmatory factor analysis of The Child Feeding Questionnaire: A Measure of parental attitudes, beliefs and practices about child feeding and obesity proneness. Appetite, 36, 201-210.

Centraal Bureau voor de Statistiek. (2006). Gerapporteerde gezondheid en leefstijl. Medische consumptie, gezondheid en aandoeningen, functiebeperkingen en leefstijl naar kenmerken van de gebruikers 2000-2005. Statline CBS: 〈http://statline.cbs.nl/statweb $\rangle$.
Clarke, W. R., \& Lauer, R. M. (1993). Does childhood obesity track into adulthood? Critical Reviews in Food Science and Nutrition, 33, 423-430.

Constanzo, P. R., \& Woody, E. Z. (1984). Parental perspectives on obesity in children: The importance of sex differences. Journal of Social and Clinical Psychology, 2, 305-313.

Corwin, R. L., Wojnicki, F. H., Fisher, J. O., Dimitriou, S. G., Rice, H. B., \& Young, M. A. (1998). Limited access to a dietary fat option affects ingestive behavior but not body composition in male rats. Physiology and Behavior, 65, 545-553.

Faith, M. S., Scanlon, K. S., Birch, L. L., Francis, L. A., \& Sherry, B. (2004). Parent-child feeding strategies and their relationships to child eating and weight status. Obesity Research, 12, 1264-1272.

Fisher, J. O., \& Birch, L. L. (1999). Restricting access to palatable foods affects children's behavioral response, food selection, and intake. American Journal of Clinical Nutrition, 69, 1711-1722.

Galloway, A. T., Fiorito, L. M., Francis, L. A., \& Birch, L. L. (2006). 'Finish your soup': Counterproductive effects of pressuring children to eat on intake and affect. Appetite, 46, 318-323.

Galloway, A. T., Fiorito, L. M., Lee, Y., \& Birch, L. L. (2001). Parental pressure, dietary patterns, and weight status in girls who are 'picky eaters'. Journal of the American Dietetic Association, 105, 541-548.

Mann, T., \& Ward, A. (2001). Forbidden fruit: Does thinking about a prohibited food lead to its consumption? International Journal of Eating Disorders, 29, 319-327.

Piaget, J. (1965). The moral judgment of the child. New York: Free Press.

Robinson, T. N., Kiernan, M., Matheson, D. M., \& Haydel, K. F. (2001). Is parental control over children's eating associated with childhood obesity? Results from a population-based sample of third graders. Obesity Research, 9, 306-312.

Rolls, E. T., \& Rolls, J. H. (1996). Olfactory sensory-specific-satiety in humans. Psychology and Behavior, 61, 461-473.

Serdula, M. K., Ivery, D., Coates, R. J., Freedman, D. S., Williamson, D. F., \& Byers, T. (1993). Do obese children become obese adults? A review of the literature. Preventive Medicine, 22, 167-177.

USDA/ARS Children's Nutrition Research Center. (2007). Children's BMI-percentile-for-age calculator. Retrieved March 22, 2007, from $\langle$ http://www.kidsnutrition.org/bodycomp/bmiz2.html $\rangle$.

van den Hurk, K., van Dommelen, P., de Wilde, J. A., Verkerk, P. H., van Buuren, S., \& HiraSing, R. A., (2006). Prevalentie van overgewicht en obesitas bij jeugdigen 4-15 jaar in de periode 2002-2004. TNO-rapport $\mathrm{KvL} / \mathrm{JPB} / 2006.010$.

Visscher, T. L., Kromhout, D., \& Seidell, J. C. (2002). Long term and recent time trends in the prevalence of obesity among Dutch men and women. International Journal of Obesity, 26, 1218-1224.

Wayner, M. J., Greenberg, I., Tartaglione, R., Nolley, D., Fraley, S., \& Cott, A. (1972). A new factor affecting the consumption of ethyl alcohol and other sapid fluids. Psychology of Behavior, 8, $345-362$. 